\title{
Ionic Oligomerization and Polymerization of 2-Alkenyl-2-oxazolines
}

\author{
D. A. Tomalia*, B. P. Thill, and M. J. FAzio \\ Designed Polymers and Chemicals Research Laboratories, \\ Dow Chemical U.S.A., \\ Midland, Michigan 48640 U.S.A.
}

(Received April 15, 1980)

\begin{abstract}
Ionic propagation of 2-alkenyl-2-oxazolines has been examined in the presence of both cationic and anionic initiators. In order to provide a basis for understanding the cationic (Brønsted acid) propagation modes, model systems involving 2-alkenyl-2-oxazolinium salts and nucleophiles were studied. Spectroscopic analysis of these salts $\left({ }^{13} \mathrm{C}\right.$ and ${ }^{1} \mathrm{H}$ NMR) predicted electrophilic activity at the 2- and 5-position of the heterocyclic ring as well as the terminal olefin carbon. Nucleophilic attack was observed at each of these positions with specificity as a function of the nucleophile type. Ketene aminal species were demonstrated to be key intermediates in the cationic propagation processes as determined by deuterium trapping experiments. Three new cationic propagation modes leading to dimeric or oligomeric products were identified and occurred as a function of the (a) acid strength, (b) proton multiplicity of the acid, and (c) nucleophilicity of the polymerization medium. Proposed propagation mechanisms are discussed. Anionic polymerization of 2-isopropenyl-2-oxazoline with butyllithium was shown to give low-molecular-weight polymers which are identical to those obtained by use of radical initiators. Finally, this study demonstrates that whereas radical and anionic polymerization of 2-alkenyl-2-oxazolines involve $\alpha$ carbon propagating species, the cationic modes proceed via $\beta$-carbon-type species.

KEY WORDS 2-Alkenyl-2-oxazolines / Anionic Polymerization / Cationic Polymerization / Ketene Aminals / Michael Addition / 2-Isopropenyl-2oxazoline / Salts / Dimers / Oligomers /
\end{abstract}

Free radical polymerization of 2-alkenyl-2oxazolines through the olefinic function has received considerable attention in the past. ${ }^{1-3}$ Likewise, cationic polymerization of the oxazoline ring has been studied extensively. ${ }^{4-6}$ Review of the literature reveals that very little has been reported on the behavior of the olefinic funtion of 2-alkenyl2-oxazolines in the presence of ionic initiators.

The object of this work, which is in two parts, is to review new developments in this general area. A study of the Brønsted-initiated dimerization/oligomerizations of 2-alkenyl-2-oxazolines is examined in Part I, whereas, Part II describes the successful polymerization of these heterocyclic monomers with anionic initiators.

\section{PART I CATIONIC DIMERIZATIONS/OLIGOMERIZATIONS}

Kagiya et al. ${ }^{3}$ reported they could selectively polymerize the oxazoline ring in 2-isopropenyl-2- oxazoline (IPO) to give linear poly $(N$-methacryloylethylenimine) with either Brønsted or Lewis acids at $75-125^{\circ} \mathrm{C}$.

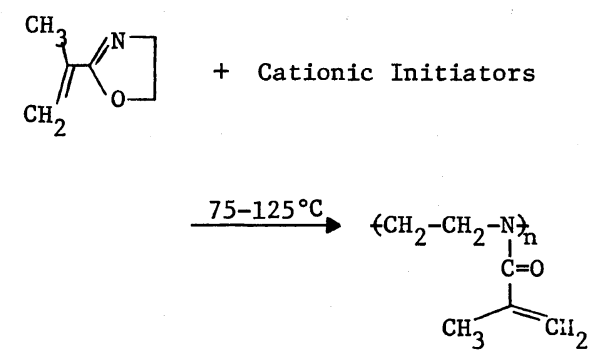

In our laboratories it has been observed for a number of years that a variety of unidentified polymers, gels or oligomeric syrups were readily formed by merely allowing 2-alkenyl-2-oxazolines to come in contact with Brønsted acids at room temperature. These propagation modes differed 
dramatically from that reported by Kagiya in several respects. First, our polymerizations were room temperature processes, whereas, Kagiya obtained better polymer yields as reaction temperatures were increased $\left(75^{\circ} \mathrm{C} \rightarrow 125^{\circ} \mathrm{C}\right)$. Secondly, we observed either complete or nearly complete loss of olefinic function in our propagation products, whereas Kagiya noted complete retention of this moiety in his polymers.

At least three different low temperature propagation types have been identified. Parameters most notably effecting the nature of the propagation products include (a) proton multiplicity of the acid, (b) acid strength, (c) nucleophilicity of the acid, and (d) nucleophilicity of the polymerization solvent. These aspects are examined in this section.

\section{RESULTS AND DISCUSSION}

Since Brønsted acids appeared to be universal propagating agents for 2-alkenyl-2-oxazolines, their incipient cations were strongly implicated in these room temperature transformations. For this reason, the ambient character of these cations was examined by proton and carbon spectroscopy. A prior prediction of potential electrophilic sites at the terminal olefin carbon, the 2-position and the 5position was confirmed by both spectroscopic techniques. As shown in Table I, proton spectroscopy indicates the 5-position protons $(\Delta \delta=0.84$ $\mathrm{ppm}$ ) to be most deshielded followed by the terminal olefin protons $(\Delta \delta=0.77 / 0.68 \mathrm{ppm})$ in the 2isopropenyl-2-oxazolinium cation. Carbon spectroscopy, however, (Table II) exhibits greatest

Table I. Spectroscopic $\left({ }^{1} \mathrm{H}\right)$ evidence for ambident cation character

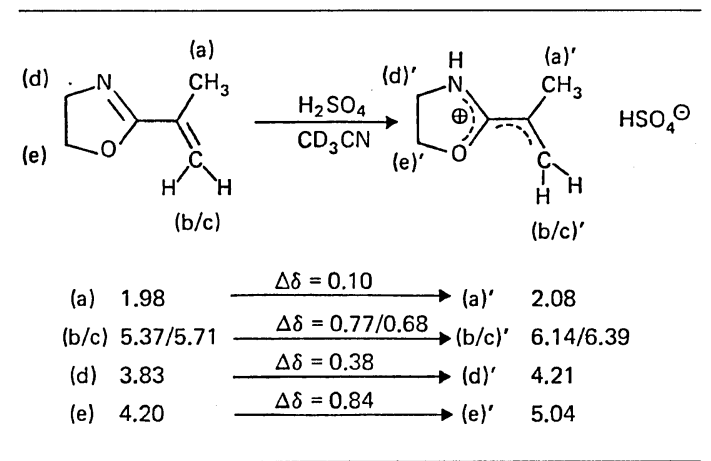

Table II. Spectroscopic $\left({ }^{13} \mathrm{C}\right)$ evidence for ambident cation character

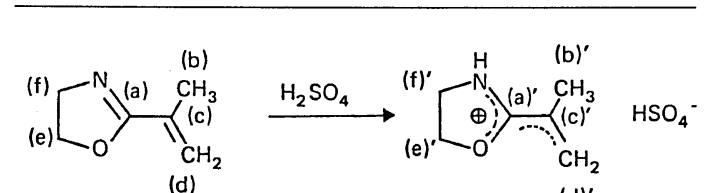

(d)

(d)'
(a) 164.7
$\stackrel{\Delta \delta=-9.0}{\longrightarrow}$ (a)' 173.7
(b) 18.4
(c) 132.5
(d) 120.7
(e) 67.0
(f) 54.2

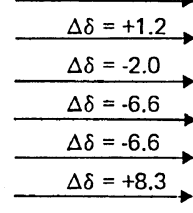
(b)' 17.2
(c) 134.5
(d) 127.3
(e) 73.6
$\longrightarrow(f)^{\prime} \quad 45.9$

deshielding at the 2-position $(\Delta=9.0 \mathrm{ppm})$ followed by comparable deshielding at both the 5-position $(\Delta \delta=6.6 \mathrm{ppm})$ and the terminal olefin carbon $(\Delta \delta=6.6 \mathrm{ppm})$.

The literature contains many examples of nucleophilic attack at the 5-position in oxazolinium cations and several examples of such reactions at the 2-position. ${ }^{8,14}$ To our knowledge, nucleophilic reactions at the terminal olefin carbons in these cations have not yet been documented.

2-Isopropenyl-2-oxazoline (IPO) does not readily undergo Michael-type reactions with nucleophilic reagents unless in the cationic form. For example, reagents such as $\mathrm{CH}_{3} \mathrm{OH}$, pyridine, $\mathrm{NaSH}$ or $\mathrm{Na}_{2} \mathrm{~S}_{2} \mathrm{O}_{3}$ did not add across the double bond of

Table III. Nucleophilic attack on 2-isopropenyl2-oxazolinium cation

\begin{tabular}{|c|c|c|c|}
\hline \multirow{2}{*}{ Nucleophilic reagent } & \multicolumn{3}{|c|}{ Reaction Site } \\
\hline & $\begin{array}{c}\text { Terminal } \\
\text { olefin } \\
\text { carbon }\end{array}$ & $2^{\circ} \mathrm{C}$ & $5^{\circ} \mathrm{C}$ \\
\hline $1 \mathrm{NaHSO}_{3}\left(\mathrm{H}_{2} \mathrm{O}\right)$ & $100 \%$ & - & - \\
\hline $2 \mathrm{Na}_{2} \mathrm{~S}_{2} \mathrm{O}_{3}\left(\mathrm{H}_{2} \mathrm{O}\right)$ & $100 \%$ & - & - \\
\hline $3 \mathrm{NaSH}\left(\mathrm{H}_{2} \mathrm{O}\right)$ & $\sim 100 \%$ & - & - \\
\hline 4 Pyridine $\left(\mathrm{H}_{2} \mathrm{O}\right)$ & $98 \%$ & $2 \%$ & - \\
\hline $\begin{array}{l}5 \text { 4-Methylpyridine } \\
\left(\mathrm{H}_{2} \mathrm{O}\right)\end{array}$ & $95 \%$ & $5 \%$ & - \\
\hline $6 \mathrm{H}_{2} \mathrm{O}$ & - & $\sim 100 \%$ & - \\
\hline $7 \mathrm{CH}_{3} \mathrm{OH}$ & $84 \%$ & - & $16 \%$ \\
\hline $8 \mathrm{HCl}$ & $\sim 15 \%$ & - & $\sim 85 \%$ \\
\hline
\end{tabular}


neutral IPO under mild conditions. These same reagents, however, Michaels added quantitatively at room temperature, in some cases, when contacted with the IPO cation (see Table III). Similarly, acidic reagents such as $\mathrm{H}_{2} \mathrm{~S}$, $\mathrm{HS}-\mathrm{CH}_{2}-\mathrm{CH}_{2}-\mathrm{OH}$ or $\mathrm{NaHSO}_{3}$ added quantitatively, thus suggesting that activation of the oxazoline by protonation was essential to effect facile nucleophilic addition at the terminal olefin carbon. Surprisingly, $\mathrm{HCl}$ reacted with IPO by nucleophilic attack at the 5-position to give primarly $N$-(2-chloroethyl)methacrylamide. Addition of water to IPO cations of strong acids (e.g., $\mathrm{X}=\mathrm{CF}_{3} \mathrm{SO}_{3}{ }^{\ominus}, \mathrm{BF}_{4}{ }^{\ominus}$ or $\mathrm{HSO}_{4}{ }^{\ominus}$ ) gave 2aminoethyl methacrylates (AEM) resulting from nucleophilic attack at the 2-position. Water reacted

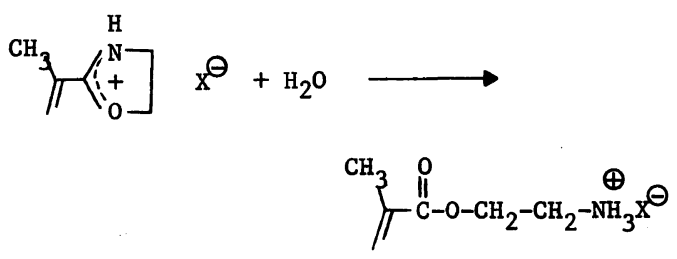

(I)

with IPO cations of weaker acids (e.g., $\mathrm{X}=\mathrm{CH}_{3} \mathrm{CO}_{2}{ }^{\ominus}$ or $\mathrm{CF}_{3} \mathrm{CO}_{2}{ }^{\ominus}$ ) to give primarily aminoester oligomers related to AEM and will be discussed later under Type II linear 2-position ring- opened oligomerization.

\section{Structure Proof for Model Michael Addition Products}

The unprecedented Michael addition of an oxazoline moiety to the olefinic group of IPO cations was suspected as a key event preceding all of the observed dimerizations and oligomerizations. Attempts to use model oxazoline compounds (e.g., 2-methyl- or 2-phenyl-2-oxazoline) were unsuccessful because the higher basicity of these oxazolines led to proton transfer giving a mixture of the 2alkyl/aryl-2-oxazolinium cations and unprotonated IPO. Furthermore, spectra of the IPO dimerization and oligomerization products were very complex, therefore it was deemed essential to demonstrate this phenomena with analogous, less basic nucleophiles which could be characterized unequivocally. For these reasons the reactions of methanol and pyridine with IPO cations were examined in considerable detail.

Methanol reacted with $\mathrm{IPOH}^{\oplus} \mathrm{BF}_{4}{ }^{\ominus}$ to give a mixture of the Michael-addition product $(84 \%$ yield) and $N$-(2-methoxyethyl)methacrylamide (16\% yield). These product structures were confirmed by NMR/infrared spectroscopy as well as elemental analysis and alternate synthesis of authentic compounds as described below:

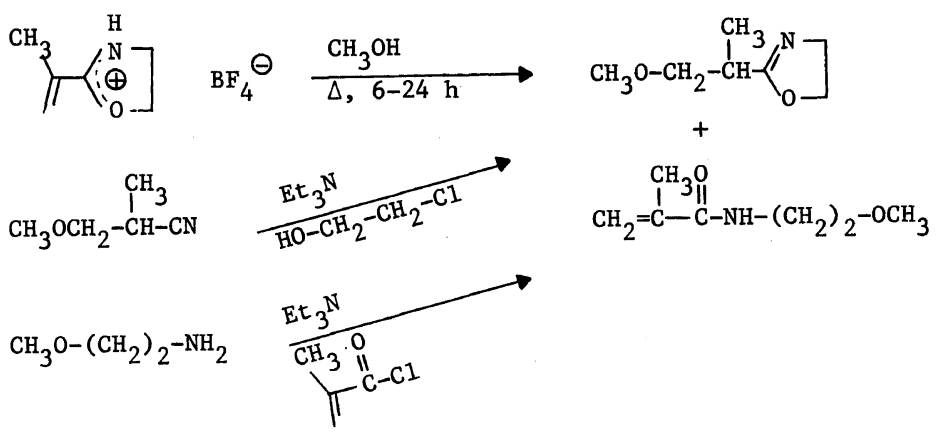

4-Methylpyridine and $\mathrm{IPOH}^{\oplus} \mathrm{HSO}_{4}{ }^{\ominus}$ in deuterium oxide gave a $95 \%$ yield of the ring-opened Michaels adduct shown below, with incorporation of deuterium on the carbon $\alpha$ to the ester function. This transformation was readily monitored by proton spectroscopy. It involved following the disappearance of characteristic resonances for the isopropenyl and oxazolinium ring protons accompanied by concurrent development of downfield doublets at $8.00 \mathrm{ppm}$ and $8.83 \mathrm{ppm}$ for the pyridinium function, a doublet at $4.92 \mathrm{ppm}$ for the $\equiv \mathrm{N}^{\oplus}-\mathrm{CH}_{2}-$ group, two triplets at $4.53 \mathrm{ppm}$ and $3.52 \mathrm{ppm}$ for the $-\mathrm{CO}_{2} \mathrm{CH}_{2}-$ and $-\mathrm{CH}_{2} \mathrm{NH}_{3}{ }^{\oplus}$ protons respectively, and upfield singlets for the aromatic $\mathrm{CH}_{3}$, $2.75 \mathrm{ppm}$, and the $-\mathrm{CH}_{2}-\mathrm{CD}\left(\mathrm{CH}_{3}\right)$ group at 1.40 ppm (see Figure 1). The unsplit signal for the methyl 


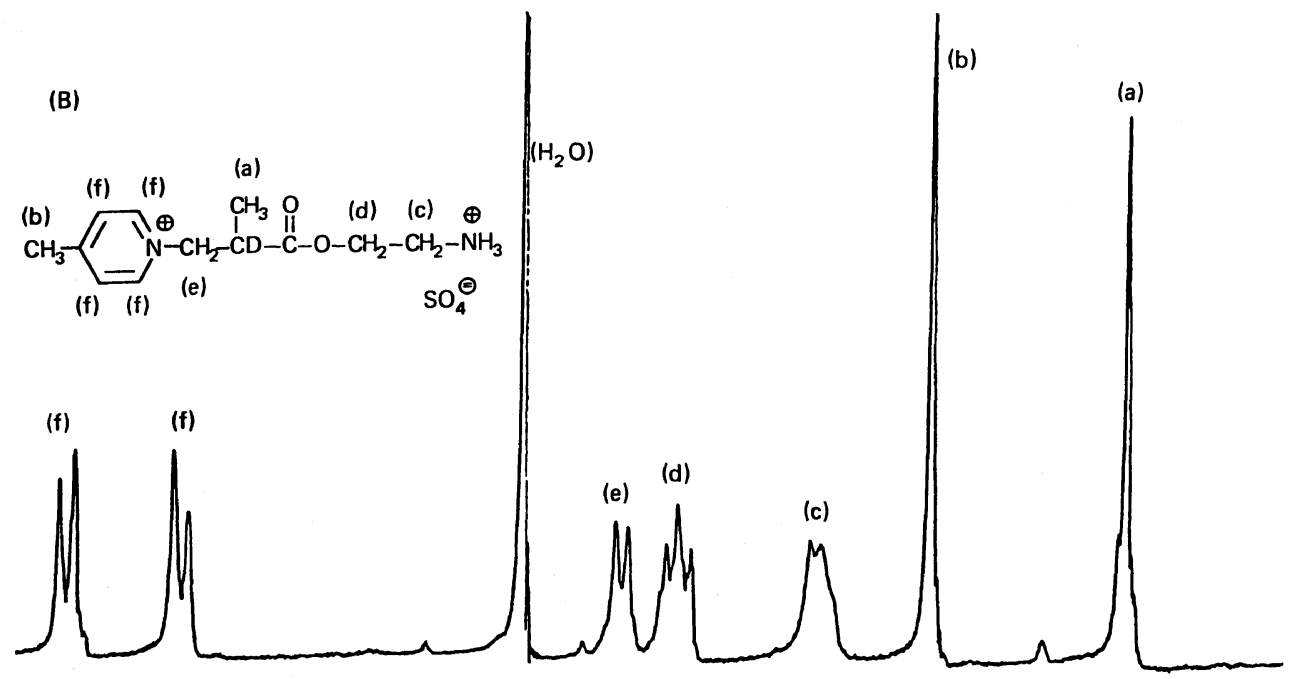

(A)

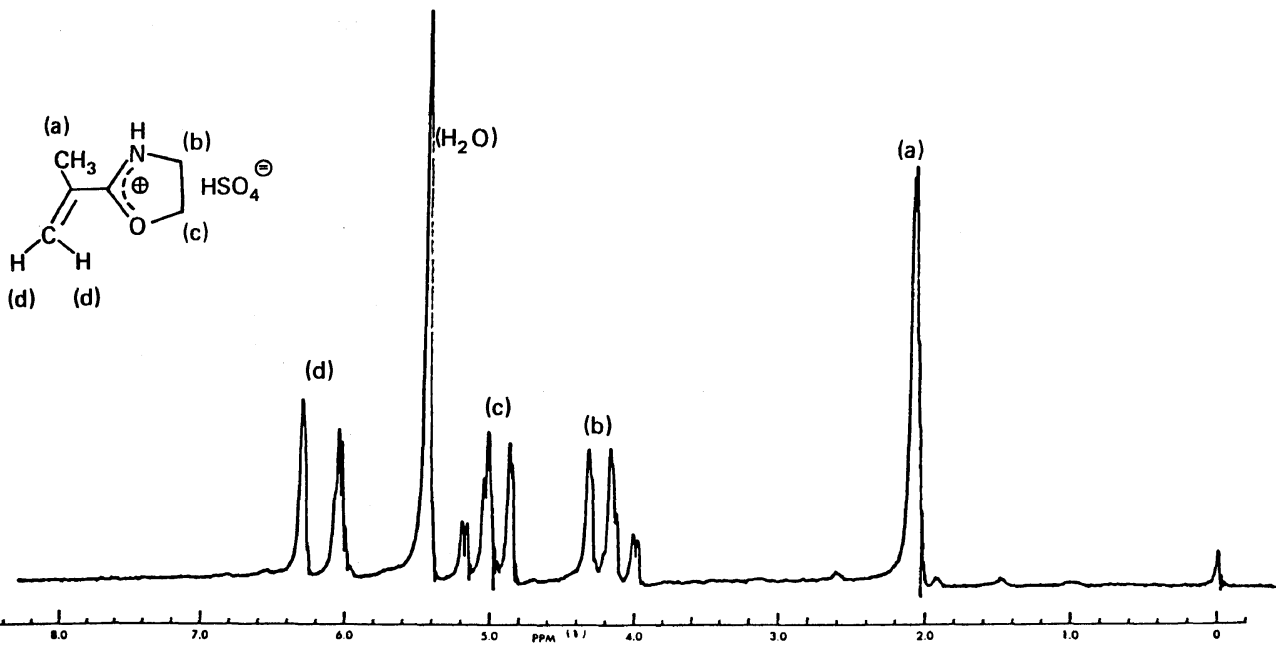

Figure 1. ${ }^{1} \mathrm{H}$ NMR spectra of 2-isopropenyl-2-oxazolinium bisulfate and Michael adduct with 4-picoline: (A) 2-Isopropenyl-2-oxazolinium bisulfate in $\mathrm{D}_{2} \mathrm{O}$; (B) Michael adduct with 4-picoline in $\mathrm{D}_{2} \mathrm{O}$.

group provided evidence for incorporation of deuterium on the $\alpha$-carbon. This same reaction in water gave a product exhibiting a sharp doublet for the methyl group and split methylene protons. It has been reported by Allen et al..$^{7}$ that under these acidic conditions that the $\alpha$-position of alkyl oxazolines do not exchange deuterium. Furthermore, the water derived aminoester adduct was shown not to exchange deuterium. Therefore these observations strongly suggest that a ketene-aminal such as (II) may play an important role in these transformations.<smiles>Cc1cc[n+](CC(C)C2NCCO2)cc1</smiles>

(II)

Although NMR and infrared spectroscopy were consistent with the proposed structure, chemical transformation to predictable products with base, provided unequivocal proof of structure. Adding one equivalent of base led to immediate and complete conversion to $\mathrm{N}$-(2-hydroxyethyl)-3-[4methylpyridinium]-2-methylpropaneamide. 
Subsequent addition of base gave a quantitative conversion to free 4-methylpyridine and $N$-(2hydroxyethyl)methacrylamide.

$$
\text { }
$$

Therefore, based on data obtained for these model systems, one might suspect a prior that mixtures of protonated and unprotonated IPO could couple to form ketene aminal-IPO quaternary adducts such as $\left(\right.$ III $\rightleftharpoons$ III'$\left.^{\prime}\right)$. Invoking the intermediacy of these adducts provides a unified

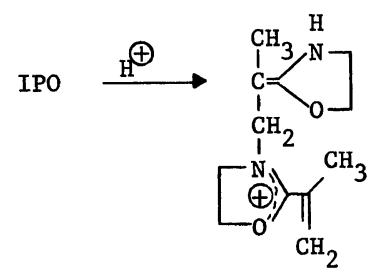

(III)

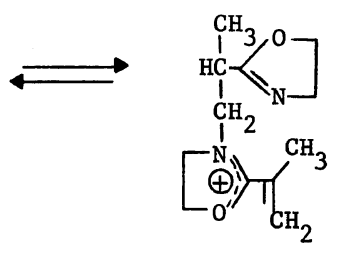

(III')

Ketene aminal-oxazoline quaternary adduct

explanation for each of the proton initiated dimerization/oligomerization modes which have been identified thus far for 2-alkenyl-2-oxazolines.

\section{Type-I. Cyclic Dimerization}

Intermediacy of the above adducts was amply demonstrated by combining stoichiometric amounts of $\mathrm{IPOH}^{\oplus} \mathrm{CF}_{4} \mathrm{SO}_{3}{ }^{\ominus}$ and IPO. An immediate exothermic reaction occurs to give $93 \%$ conversion to a mixture of the six-membered dimer $(\mathbf{V}),(82 \mathrm{~mol} \%)$ and the eight-membered dimeric dication $\left(\mathbf{V}^{\prime}\right),(18$ mol\%). Dimers $(\mathbf{V})$ and $\left(\mathbf{V}^{\prime}\right)$ were isolated as white solids; (V),

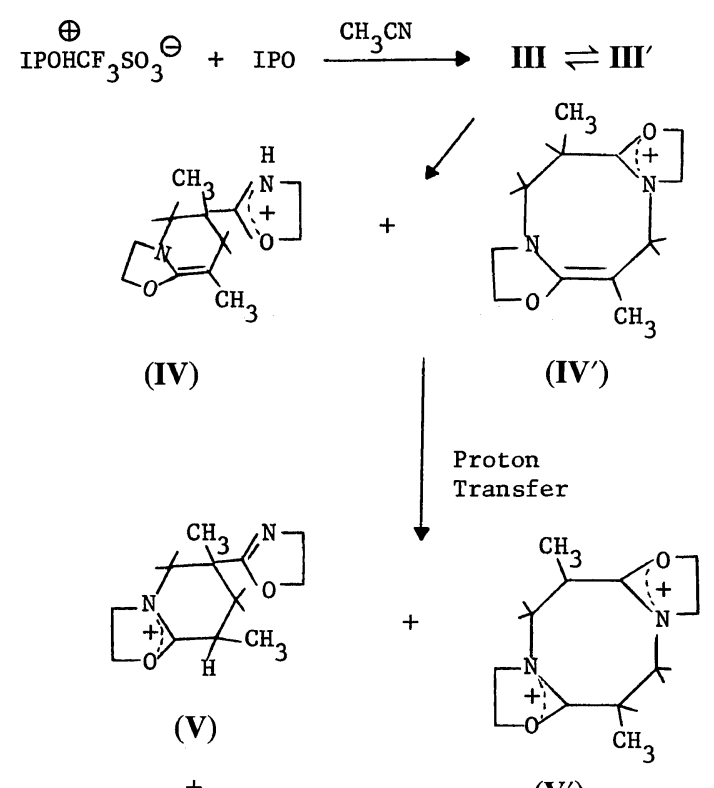

unprotonated (IV)

$\left(\mathbf{V}^{\prime}\right)$

mp $94-98^{\circ} \mathrm{C} ;\left(\mathbf{V}^{\prime}\right), \mathrm{mp} 216-217^{\circ} \mathrm{C}$. Insolubility of $\left(\mathbf{V}^{\prime}\right)$ in acetonitrile, allowed separation of the two dimers.

Structure proof for dimer (V) was garnered primarily by ${ }^{1} \mathrm{H}$ and ${ }^{13} \mathrm{C}$ spectroscopy as well as by its hydrolytic properties. Figure 2 illustrates the proton spectrum and tentative assignments for the monocation (V) unprotonated (IV) mixture. Further protonation of this (IV)-(V) mixture with triflic acid was both revealing and diagnostic. Sequential protonation caused protons (c) to move downfield and merge with (a), whereas protons (d) shifted downfield slightly as would be predicted for dication formation from (V). Dication formation from (V) also caused predictable downfield separation of a methyl singlet assigned to methyl group (k) which is $\alpha$ to the pendant oxazoline ring. In both the monocation and dication of $(\mathbf{V})$ the proton 


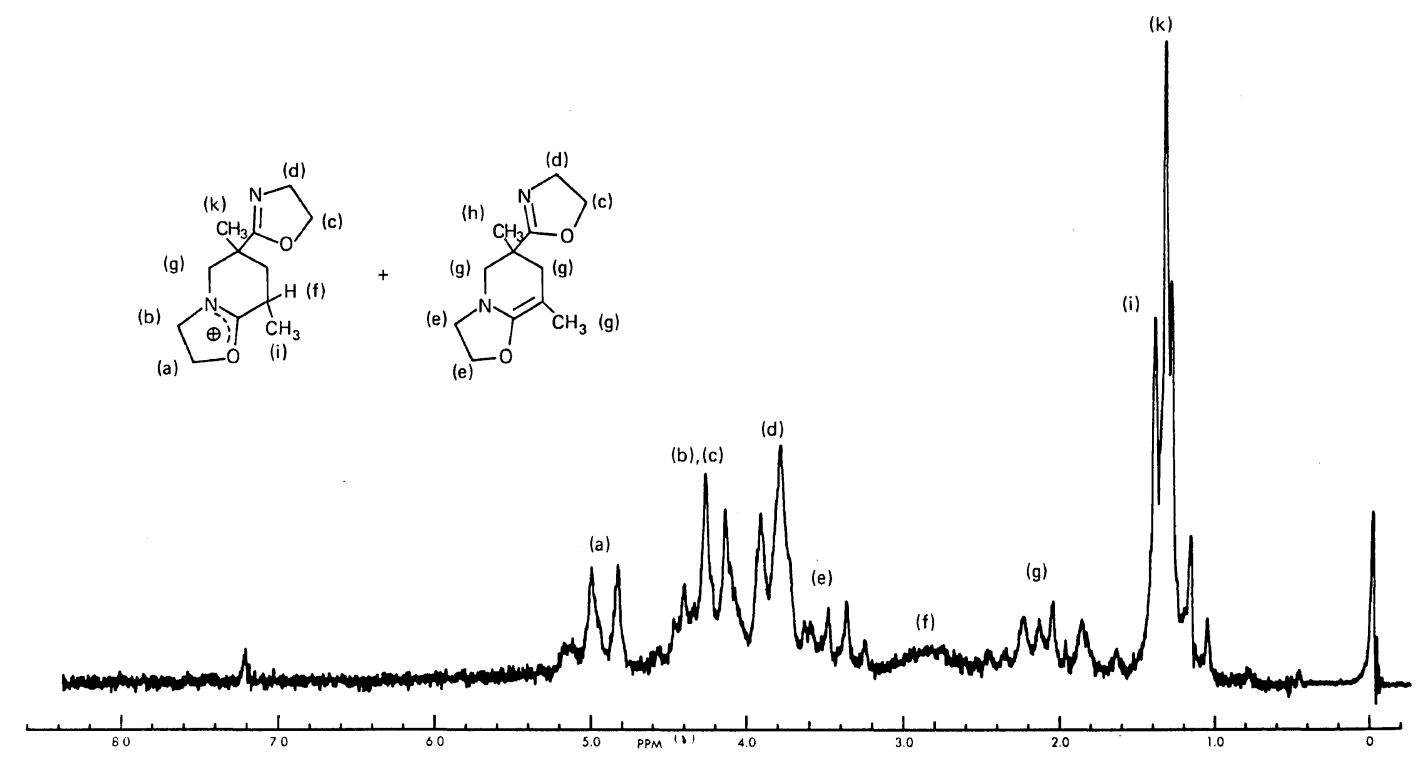

Figure 2. ${ }^{1} \mathrm{H}$ NMR spectrum of monoprotonated and unprotonated six-membered cyclic dimer of 2isopropenyl-2-oxazoline in $\mathrm{CDCl}_{3}$.
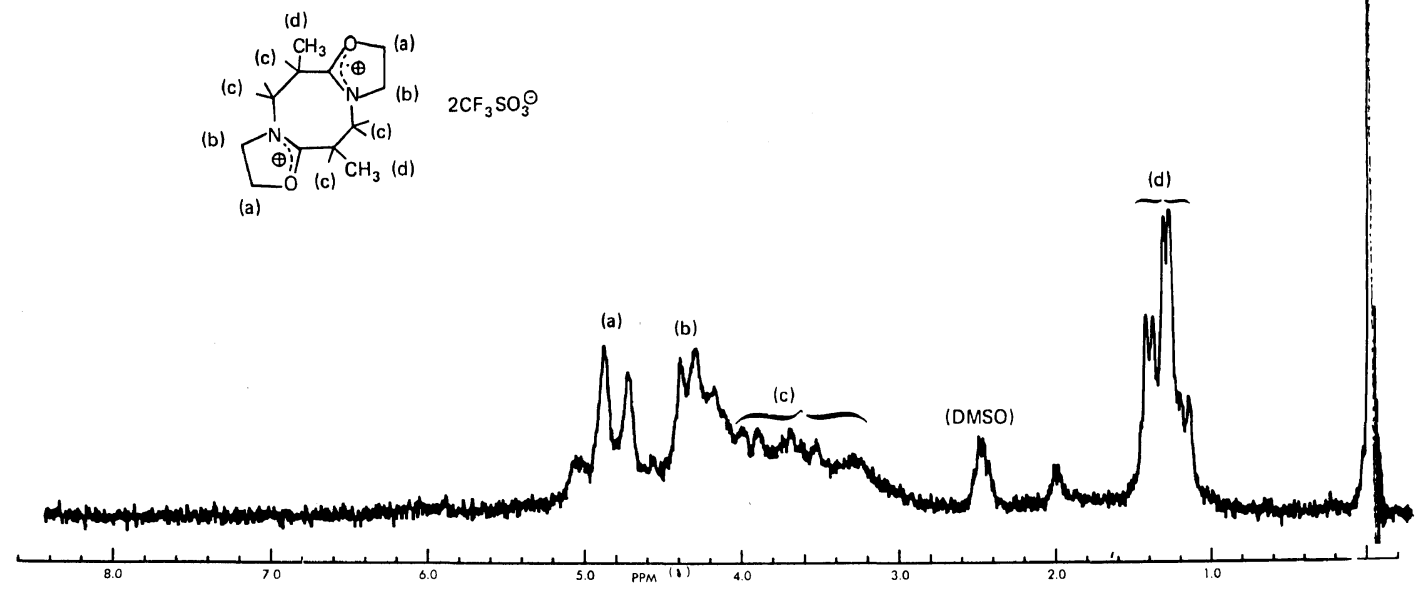

Figure 3. ${ }^{1} \mathrm{H}$ NMR spectrum of eight-membered cyclic dimer (dication) of 2-isopropenyl-2-oxazoline in DMSO- $d_{6}$.

integrations were consistent with the proposed assignments.

Another feature which distinguishes dimer (V) from dimer $\left(\mathbf{V}^{\prime}\right)$ is the fact that the pendant oxazoline ring in dimer $(\mathbf{V})$ would be predictably more stable ${ }^{8}$ to hydrolytic ring-opening compared to the other fused oxazoline ring in dimer (V) or those fused rings in dimer $\left(\mathbf{V}^{\prime}\right)$. Hydrolysis of the lower-melting presumed dimer $(\mathbf{V})$ confirmed this point in that one of the oxazoline rings resisted hydrolysis. In the higher melting, presumed eightmembered cyclic dimer $\left(\mathbf{V}^{\prime}\right)$, both oxazoline rings 
hydrolyzed under very mild conditions.

The cyclic eight-membered dimer structure $\left(\mathbf{V}^{\prime}\right)$ was supported by proton spectroscopy and elemental analysis. Figure 3 shows the proton spectrum with tentative assignments, giving integral values consistent with the proposed structure. The complexity of the methyl region is believed to be due to slight difference in chemical shifts resulting from preferred conformations for this system. As mentioned earlier, hydrolysis of both fused oxazoline rings was rapid and complete under mild conditions. Although not thoroughly characterized, the hydrolysis products appears to be predominately a fourteen-membered macrocyclic aminoester resulting from hydrolytic fission at the fused ring junction followed by ring expansion. This conjecture is based on the resonance pattern and chemical shifts which approximate known aminoester derivatives. It was interesting to note that complexity of the methyl region in Figure 3 reduced to a well defined doublet as might be expected for the proposed hydrolysis product.

Formation of $(\mathbf{V})$ and $\left(\mathbf{V}^{\prime}\right)$ clearly demonstrates the intermediacy of the adducts (III) and (III'). Formation of the six-membered cyclic dimer (V) as the major product indicates intramolecular capture of the ketene aminal is extremely facile and may occur faster than tautomerization to the oxazoline tautomer (III'). These observations provide a rational hypothesis for understanding the Type IIIII oligomerizations.

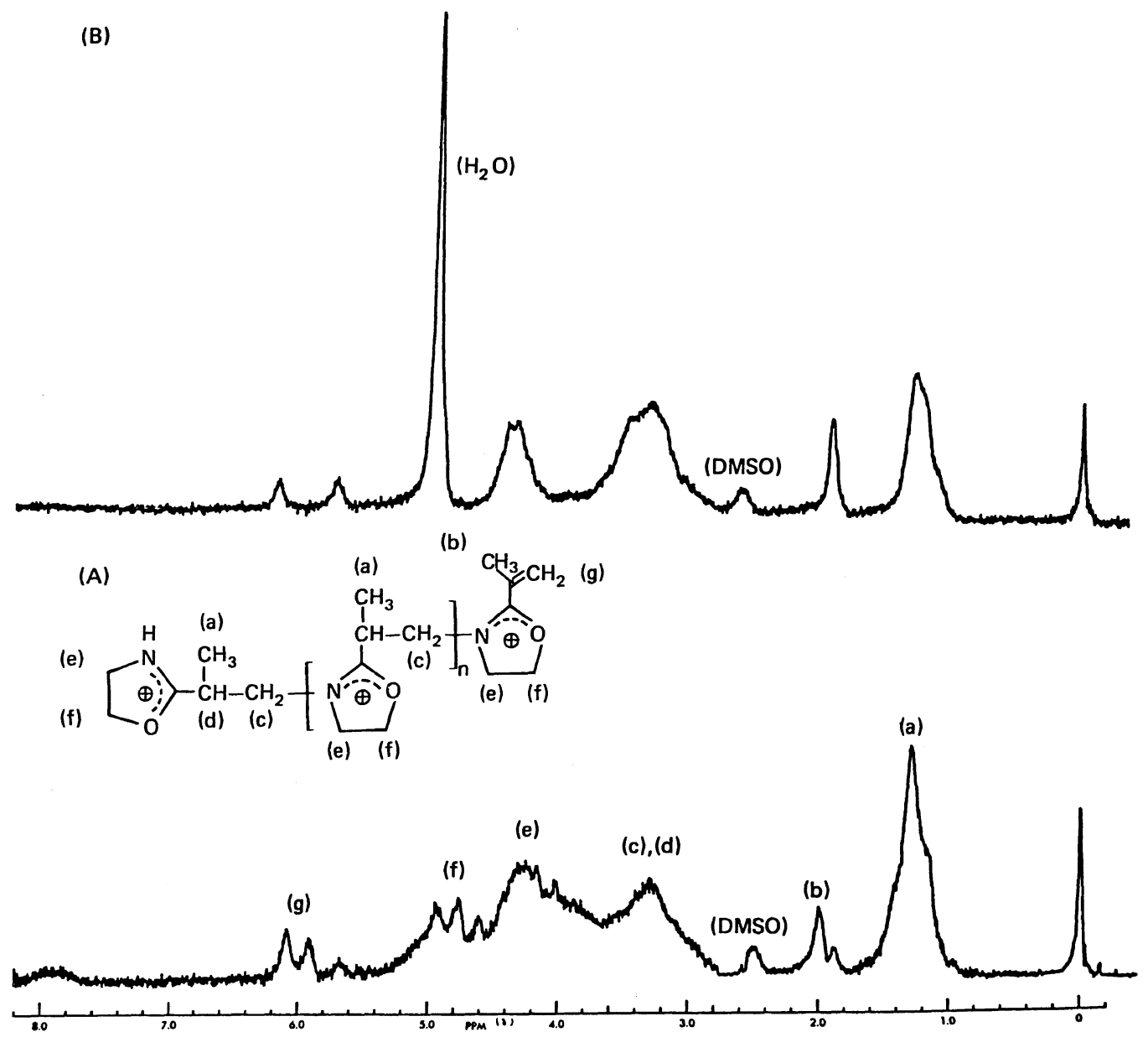

Figure 4. ${ }^{1} \mathrm{H}$ NMR spectra of Type II linear ring preserved oligomer and hydrolysis product: (a) Type II oligomer in DMSO- $d_{6}$; (B) Type II oligomer hydrolysis product in (DMSO-d $d_{6}, \mathrm{D}_{2} \mathrm{O}$, and $\mathrm{CF}_{3} \mathrm{CO}_{2} \mathrm{H}$ ). 


\section{Type-II. Linear Ring-Preserved Oligomerization}

Combining stoichiometric amounts of $\mathrm{IPOH}^{\oplus} \mathrm{HSO}_{4}{ }^{\ominus}$ and IPO under conditions identical to that described for Type-I dimerization gave oligomeric products rather than dimers. The oligomers were isolated in $75-80 \%$ yield as moisture sensitive white solids which readily formed solvates derived from the acetonitrile solvent. The broad, less well defined proton spectrum in Figure 4 (A) clearly illustrates the polymeric nature of this product. Although this spectrum contains appropriate signals at 4.77 and $4.23 \mathrm{ppm}$ for quaternized oxazoline rings and upfield methyl resonances at $1.27 \mathrm{ppm}$ for a Michael-type product, a very unique feature which distinguishes it from the dimer products is the presence of olefin protons at 6.03 and $5.90 \mathrm{ppm}$. Molecular weights of these products varied between $900-2500$ as determined by vaporphase osmometry. These products hydrolyzed very readily in water with loss of oxazoline rings to gave a viscous oligomeric aminoester product as determined by NMR (Figure 4 (B)) and infrared spectroscopy. This hydrolysis product was identical to those obtained by direct combination of IPO salts with IPO in aqueous media and will be discussed in more detail under Type-III oligomers.

A polymeric structure which is most consistent with the above data is that derived from nucleophilic attack at the terminal olefin carbon of the ketene aminal-oxazoline adducts (III) and (III') by neutral IPO as shown below:

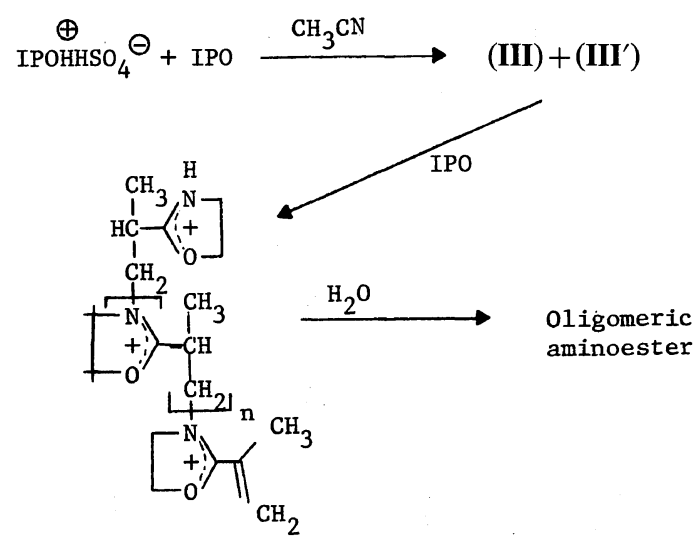

One must question why the IPO cation derived from a monoprotic acid (e.g., triflic acid) leads to predominately Type-I dimeric products, whereas, an IPO cation derived from a diprotic acid (e.g., sulfuric acid) gives mostly Type-II linear ring preserved oligomers. A rational explanation for these observations may be that in the case of the Type-I dimerizations there are no surplus protons to protect the nucleophilic portions of the ketene aminal-oxazoline adduct (III) and (III'). When using a diprotic acid, the acidity of the $\mathrm{HSO}_{4}{ }^{\ominus}$ group may be sufficient to protonate (III) and (III'), thus inhibiting intramolecular dimerization and favoring oligomerization. Ketene aminal moieties formed during oligomerization may also be protected by such a mechanism, however, there is some evidence that branching may occur by interception of these sites with $\mathrm{IPOH}^{\oplus} \mathrm{HSO}_{4}{ }^{\ominus}$. Evidence for this type of reaction is the fact that integral values for the unquaternized oxazoline ring region (i.e., $\delta \cong 4.25 \mathrm{ppm}$ and $\cong 3.83 \mathrm{ppm}$ ) are usually higher than theory when compared to the

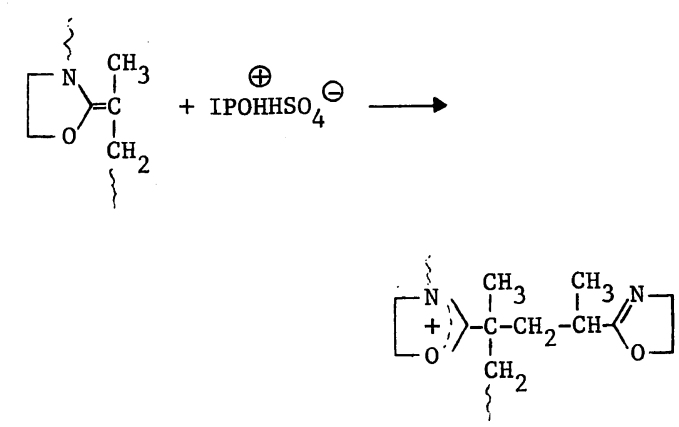

quaternized ozaoline ring region (i.e., $\delta=4.77 \mathrm{ppm}$ ). Longer reaction times appear to favor this branching phenomena. Additional evidence includes the fact that more hydrolytic stable oxazolinium moieties are generated as a function of this presumed branching. This is readily rationalized by noting that each branching site generates an oxazolinium moiety which possesses a highly hindered, neopentyl like 2-position, thus resistance to hydrolysis at these branching sites would be expected.

End-group analysis which involved comparing the integral values for the terminal olefin protons to that for the methyl group (i.e., $\delta=1.20 \mathrm{ppm}$ ) by Michael addition gave values for $n$ of 5-7. Considerable error may be present in such an analysis, however, since chain terminating events may involved Type-I cyclic dimer formation. Such events would have the effect of reducing olefinic integral values while enhancing the methyl integral values, thus inflating the calculated degree of 

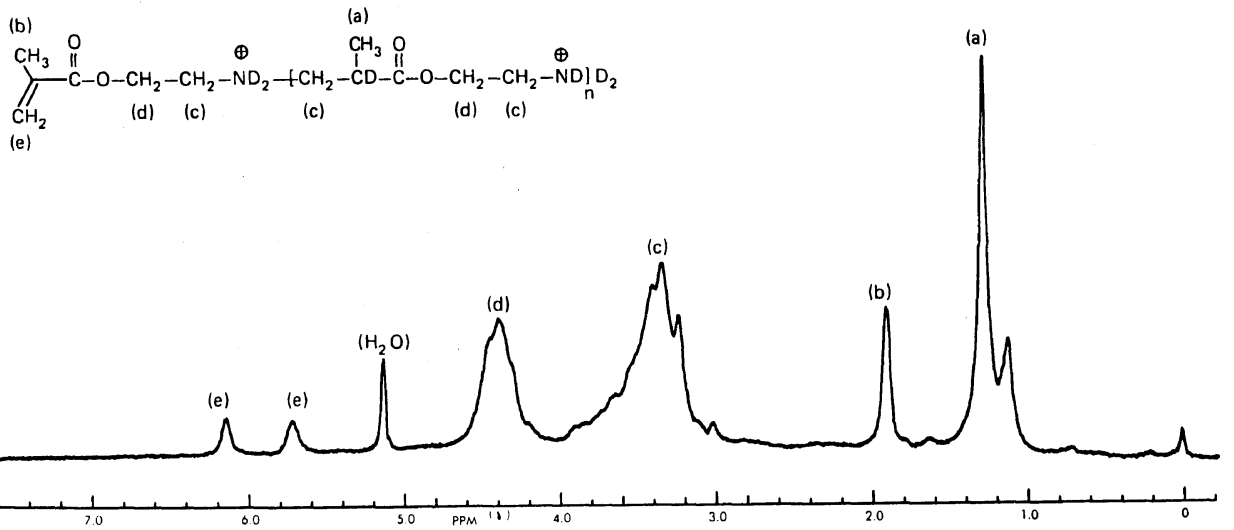

Figure 5. ${ }^{1} \mathrm{H}$ NMR spectrum of Type III linear 2-position ring-opened oligomer in $\left(\mathrm{D}_{2} \mathrm{O}, \mathrm{CD}_{3} \mathrm{CO}_{2} \mathrm{D}\right.$, and $\mathrm{CF}_{3} \mathrm{CO}_{2} \mathrm{H}$ ).

oligomerization.

Type-III. Linear 2-Position Ring-Opened Oligomers Conversion of IPO to aminoester-type oligomers can be initiated by combining the monomer with $5-50 \mathrm{~mol} \%$ of strong acids (e.g., $\mathrm{H}_{2} \mathrm{SO}_{4}, \mathrm{HCl}$, $\mathrm{CF}_{3} \mathrm{SO}_{3} \mathrm{H}$ ) or water-soluble carboxylic acids (e.g., $\left.\mathrm{CH}_{3} \mathrm{CO}_{2} \mathrm{H}\right)$ in an aqueous medium. The oligomerizations are usually complete in several hours at room temperature giving colorless, viscous products. These products eventually convert to waterswellable gellatinous masses upon standing for several days. Proton and $\mathrm{C}^{13}$ spectroscopy were used to characterize these products. A typical spectrum is shown in Figure 5 and contains characteristic olefin proton resonances at 6.13 and $5.70 \mathrm{ppm}$, aminoester-type methylene protons at $4.40 \mathrm{ppm}$ and $3.34 \mathrm{ppm}$ as well as a singlet for the olefinic methyl at $1.90 \mathrm{ppm}$. The signal at $1.23 \mathrm{ppm}$ results from the Michael-addition-type methyl groups. Infrared and $\mathrm{C}^{13}$ spectroscopy confirmed the loss of oxazoline functionality and the presence of aminoester moieties most consistent with an oligomeric structure as shown below:

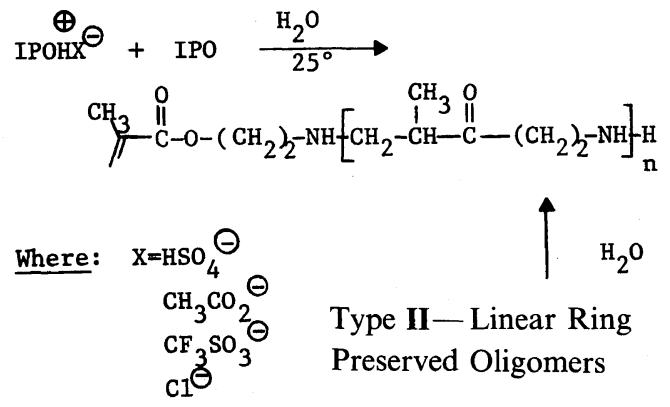

High-pressure liquid chromatography and proton spectroscopy were used to monitor the loss of oxazoline and formation of linear dimers and highers. Linear-dimer formation $(n=1)$ increased dramatically as one increased the acid concentration. At lower acid concentration, one can obtain oligomers with $n \cong 15$ as determined by end group analysis, albeit in low yield. Higher oligomers were also obtained by using weaker acids even in stoichiometric quantities. For example, Figure 5 shows an oligomer, $n=4.75$, which was obtained by combining stoichiometric amounts of IPO and
$\mathrm{CD}_{3} \mathrm{CO}_{2} \mathrm{D}$ in $\mathrm{D}_{2} \mathrm{O}$. Degree of oligomerization was determined by comparing the relative integral values for the olefin methyl group and the upfield methyl group resulting from Michael addition.

Additional evidence supporting these oligomeric structures includes the facile hydrolysis of Type-II linear-ring preserved oligomers to these products. Proton spectroscopy showed that the hydrolysis was complete in several hours, giving products which were idential in all respects.

Oligomerizations in deuterium oxide gave products exhibiting broad singlets in the methyl region 
at $1.23 \mathrm{ppm}$. Water derived oligomers displayed well defined doublets in this region thus demonstrating deuterium trapping at the position $\alpha$ to the ester carbonyl.

By analogy to the model systems, one might postulate initial formation of the ketene aminaloxazoline adducts (III) and (III'). Introduction of deuterium $\alpha$ to the ester carbonyl, no doubt, involves deuterium oxide attack at the 2-position of the newly formed oxazolinium cation to give the deuterated aminoester function as shown below:
The more facile hydrolysis of alkyl-substituted oxazoline moieties (Ring A) compared to alkenylsubstituted oxazoline moieties (Ring B), may explain why linear oligomerization is preferred over intramolecular cyclizations to dimers or cyclic end groups.

Finally, control experiments involving the conjugate addition of pyridine to 2-aminoethyl methacrylate salts showed no detectable amounts of Michael adduct was formed after 24 hours, whereas addition to $\mathrm{IPOH}^{\oplus} \mathrm{HSO}_{4}{ }^{\ominus}$ was $95 \%$ complete in less
(A)

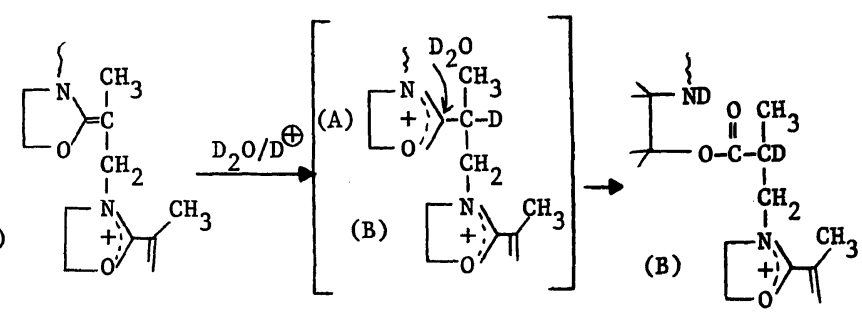

than an hour. Furthermore, Michael addition of the hydrolyzed $\mathrm{IPOH}^{\oplus} \mathrm{HSO}_{4}{ }^{\ominus}$ product (aminoester) to itself, was excluded in that storage at room temperature for 2 months at $\mathrm{pH}=1-3$ showed no increase in dimers or higher oligomers. Increasing the $\mathrm{pH}>3$ caused clean rearrangement to $\mathrm{N}$-(2hydroxyethyl)methacrylamide thereby supporting the proposed ketene aminal-oxazoline adduct mechanism.

\section{PART II. ANIONIC POLYMERIZATION}

Polymerization of 2-vinyl-4,4,6-trimethyldihydro-1,3-oxazine with butyllithium has been documented by Meyers et al. ${ }^{9}$ In contast, Fujioka and coworkers ${ }^{10}$ reported that closely related 2alkenyl-2-oxazolines did not polymerize in the presence of traditional anionic initiators. Prompted by this dichotomy, a cursory examination of the area was undertaken.

\section{RESULTS AND DISCUSSION}

2-Alkenyl-2-oxazolines have been successfully polymerized at low temperature $\left(-78^{\circ} \mathrm{C}\right.$ to $\left.0^{\circ} \mathrm{C}\right)$ in the presence of butyllithium. The products were identified as poly(2-alkenyl-2-oxazoline)s

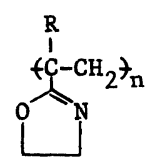

Where: $\mathrm{R}=\mathrm{CH}_{3}$ or $\mathrm{H}$ identical in all respects to those polymers obtained by radical initiators. Anionically derived polymers were obtained in $85-95 \%$ yield as white, friable powders with molecular weights of $1500-2500$. Careful purification of all reagents and solvents as well as an inert atmosphere ${ }^{13}$ are crucial to the success of the polymerizations. Attempts to produce higher-molecular-weight products by use of lower anionic initiator concentrations were futile in the case of IPO. A possible chain-transfer sequence might be envisioned as follows. 


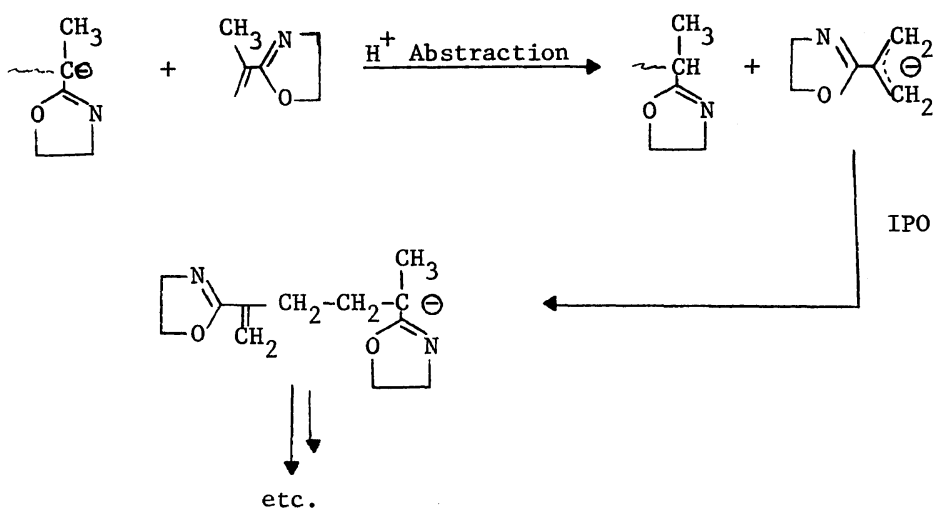

Polymers derived from each initiator source were characterized by proton, ${ }^{13} \mathrm{C}$ and infrared spectroscopy.

In conclusion, it has now been shown that 2alkenyl-2-oxazolines are highly versatile monomers which are responsive to propagation through the olefinic moiety by either radical, anionic or cationic initiators. Finally, whereas radical and anionic polymerizations involve $\alpha$-carbon propagation species (VI), the cationic modes proceed via $\beta$-carbon type species (VII).

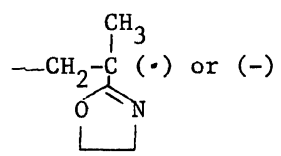

(VI)

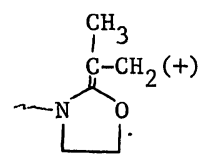

(VII)

\section{EXPERIMENTAL}

\section{Reagents}

All deuterated reagents were obtained from Stohler Isotope Chemicals, Rutherford, N. J. Solvents were spectroscopic grade, distilled in glass (Burdick and Jackson Labs., Muskegon, Mich.) and used as is. Brønsted acids were analytical grade (J. T. Baker Chemical Co., Phillipsburg, N. J.). 2Isopropenyl-2-oxazoline (IPO) was synthesized according to the method of Kagiya ${ }^{3}$ twice distilled, bp $55^{\circ} \mathrm{C}(20 \mathrm{mmHg})$ and stored over molecular sieves.

\section{Measurements}

Infrared spectra were obtained on a Perkin-Elmer Model 598 spectrometer. ${ }^{1} \mathrm{H}$ NMR spectra were scanned on a Varian T-60 spectrometer with resonances recorded relative to tetramethylsilane.
${ }^{13} \mathrm{C}$ spectra were obtained on a JEOL FX-60 spectrometer with dioxane as an internal reference. Linear dimers and oligomers were monitored by HPLC with a $25 \mathrm{~cm} \times 4.6 \mathrm{~mm}$ ID column packed with Whatman Partisil PSX 10/25 SCX, U.V. detector $(214 \mathrm{~m} \mu)$, eluent $0.18 \mathrm{M} \mathrm{KH}_{2} \mathrm{PO}_{4}, 1 \%$ $\mathrm{CH}_{3} \mathrm{PO}_{4}, 1 \% \mathrm{CH}_{3} \mathrm{CN}, \mathrm{pH} 3-3.5,1.8 \mathrm{ml} \mathrm{min}^{-1}$.

\section{2-Isopropenyl-2-oxazolinium Salts}

These salts were prepared by dropwise addition of stoichiometric amounts of IPO to a vigorously stirred solution of anhydrous acid in either acetonitrile or diethyl ether. Addition of ether caused precipitation of addition salt from acetonitrile reaction mixtures. Salts prepared included:

(a) IPO $\cdot \mathrm{H}_{2} \mathrm{SO}_{4}$ (acetonitrile); white needles $\left(\mathrm{CH}_{3} \mathrm{NO}_{2}\right.$-acetone); mp $96.5-97.3^{\circ} \mathrm{C}$; yield, $95 \%$.

Anal. Clacd for $\mathrm{C}_{6} \mathrm{H}_{11} \mathrm{NO}_{5} \mathrm{~S}: \mathrm{C}, 34.4 \%, \mathrm{H}$, $5.30 \%$, N, $6.70 \%$. Found: C, $34.4 \%$, H, $5.32 \%, \mathrm{~N}, 6.60 \%$.

(b) IPO $\cdot \mathrm{CF}_{3} \mathrm{CO}_{2} \mathrm{H}$ (diethyl ether); white powder; $\mathrm{mp} 66^{\circ} \mathrm{C}$; yield, $92 \%$.

Anal. Calcd for $\mathrm{C}_{8} \mathrm{H}_{10} \mathrm{NF}_{3} \mathrm{O}_{3}: \mathrm{C}, 43.6 \% \mathrm{H}$, $4.44 \%, \mathrm{~N}, 6.22 \%$ Found: C, $43.4 \%, \mathrm{H}$, $4.38 \%, \mathrm{~N}, 6.17 \%$.

(c) IPO $\cdot \mathrm{CF}_{3} \mathrm{SO}_{3} \mathrm{H}$ (acetonitrile); white fluffy solid; $\mathrm{mp} 80-81^{\circ} \mathrm{C}$; yield, $76^{\circ} \%$.

Anal. Calcd for $\mathrm{C}_{7} \mathrm{H}_{10} \mathrm{NF}_{3} \mathrm{O}_{4} \mathrm{~S}: \mathrm{C}, 32.2 \%$, $\mathrm{H}, 3.80 \%$, N, $5.40 \%$. Found: C, $32.4 \%$, H, $3.83 \%, \mathrm{~N}, 5.58 \%$.

(d) $\mathrm{IPO} \cdot \mathrm{HBF}_{4}$ was prepared by cyclization of $N(-2$-chloroethyl)methacrylamide prepared from aziridine and the acid chloride by the method of Bestian ${ }^{12}$ with silver tetrafluoroborate in methylene chloride. 
White needles; $\mathrm{mp} 98-100^{\circ} \mathrm{C}$; yield, $98 \%$.

\section{2-( $\beta$-Methoxyisopropyl)-2-oxazoline}

3-Methoxy-2-methylpropionitrile was prepared according to the method of Beiber. ${ }^{11}$ A stoichiometric amount of this nitrile $19.83 \mathrm{~g}(0.2 \mathrm{~mol})$ and ethylene chlorohydrin $(16.1 \mathrm{~g}, 0.2 \mathrm{~mol})$ and $\mathrm{CH}_{2} \mathrm{Cl}_{2}(80 \mathrm{ml})$ were combined and saturated with dry $\mathrm{HCl}$ under $60 \mathrm{mmHg}$ pressure over a period of 1.5 hours while stirring and cooling at $0-5^{\circ} \mathrm{C}$. The clear, homogeneous reaction mixture was alllowed to stand at $0-10^{\circ} \mathrm{C}$ overnight. An additional $120 \mathrm{ml}$ of anhydrous $\mathrm{CH}_{2} \mathrm{Cl}_{2}$ was added and the reaction mixture was refluxed at $32-34^{\circ} \mathrm{C}(575 \mathrm{mmHg})$ for 2 hours. Triethylamine $(46.6 \mathrm{~g}, 0.46 \mathrm{~mol})$ was added over a period of $15 \mathrm{~min}$. The thick slurry was refluxed for 4 hours, the amine salt was filtered off and the filterate reduced to $1 / 4$ original volume followed by dilution with diethyl ether. The remaining $\mathrm{Et}_{3} \mathrm{~N} \cdot \mathrm{HCl}$ was filtered giving a filtrate which, after removal of solvent, left $26.12 \mathrm{~g} \mathrm{(91 \% )}$ of a light yellow crude product. Distillation gave $22.38 \mathrm{~g}$ of oxazoline product boiling at $82-83.5^{\circ} \mathrm{C}(18$ $17.5 \mathrm{mmHg}$.

Anal. Calcd for $\mathrm{C}_{7} \mathrm{H}_{13} \mathrm{NO}_{2}: \mathrm{C}, 58.7 \%, \mathrm{H}, 9.15 \%$, $\mathrm{N}, 9.78 \%$. Found: C, $58.7 \% \mathrm{H}, 9.20 \%, \mathrm{~N}, 9.90 \%$. The ${ }^{1} \mathrm{H}$ NMR spectrum $\left(\mathrm{CCl}_{4}\right)$ exhibited the following features: $\delta 1.14(\mathrm{~d},(3 \mathrm{H}), J=7.1 \mathrm{~Hz}, 2.62$ $(\mathrm{q},(1 \mathrm{H})), 3.29(\mathrm{~s},(3 \mathrm{H}))$, and $3.0-4.4 \mathrm{ppm}$ (complex multiplet, $(6 \mathrm{H})$ ). The infrared $\left(\mathrm{CCl}_{4}\right)$ showed bands at $2990,2850,2790,1674,1497,1465,1402,1105$, and $952 \mathrm{~cm}^{-1}$. This product was identical in all respects to that obtained from $\mathrm{IPO} \cdot \mathrm{HBF}_{4}$ and methanol.

\section{$N$-(2-Methoxyethyl)methacrylamide}

Methacryloyl chloride $(10.45 \mathrm{~g}, 0.1 \mathrm{~mol})$ in $25 \mathrm{ml}$ of $\mathrm{CH}_{2} \mathrm{Cl}_{2}$ was added dropwise to a stirred solution of 2-methoxyethylamine $(7.51 \mathrm{~g}, 0.1 \mathrm{~mol})$ and triethylamine $(10.1 \mathrm{~g}, 0.1 \mathrm{~mol})$ in $25 \mathrm{ml}$ of $\mathrm{CH}_{2} \mathrm{Cl}_{2}$ with ice-bath cooling, allowed to warm to room temperature, filtered and washed with water $(2 \times 10 \mathrm{ml})$ and once with $(10 \mathrm{ml}$ saturated $\mathrm{NaCl}$ solution). After drying over anhydrous $\mathrm{CaSO}_{4}$, $N, N$-diphenyl-p-phenylenediamine $(10 \mathrm{ml})$ was added and distillation gave $8.52 \mathrm{~g}(59 \%)$ of product, bp $73-75.4 \%$ ( $0.7 \mathrm{mmHg})$.

Anal. Calcd for $\mathrm{C}_{7} \mathrm{H}_{13} \mathrm{NO}_{2}$ : C, $58.7 \%, \mathrm{H}, 9.15 \%$, $\mathrm{N}, 9.78 \%$. Found: C, $58.8 \%, \mathrm{H}, 9.16 \%, \mathrm{~N}, 9.70 \%$. The ${ }^{1} \mathrm{H}$ NMR spectrum $\left(\mathrm{CCl}_{4}\right)$ showed the following resonances: $\delta 1.92(\mathrm{~d},(3.04 \mathrm{H})), 3.30(\mathrm{~s},(3.05 \mathrm{H})), 3.40$ (two superimposed singlets, $(4.07 \mathrm{H})$ ), 5.24 (q, $(0.94 \mathrm{H})$ ), and 5.68 (broad s, $(0.98 \mathrm{H}))$. Infrared spectrum exhibited absorptions at $3480,3385,3104$, $3000,2845,2810,1678,1640,1460,1390$, and 1122 $\mathrm{cm}^{-1}$. This product was identical in all respects with that obtained from IPO $\cdot \mathrm{HBF}_{4}$ and methanol.

\section{Reaction of IPO $\cdot \mathrm{HBF}_{4}$ with Methanol}

$\mathrm{IPO} \cdot \mathrm{HBF}_{4}(2.0 \mathrm{~g}, 0.01 \mathrm{~mol})$ was combined with $20 \mathrm{mg}$ phenothiazine in $25 \mathrm{~g}$ of anhydrous $\mathrm{CH}_{3} \mathrm{OH}$ (distilled from $\left.\mathrm{Mg}\left(\mathrm{OCH}_{3}\right)_{2}\right)$ and refluxed for 2 hours. Removal of solvent gave $2.17 \mathrm{~g}$ of product which by NMR analysis was estimated to contain $50 \mathrm{ml} \% \quad$ IPO $\cdot \mathrm{HBF}_{4}, \quad 42 \quad \mathrm{~mol} \% \quad 2-(\beta$-methoxyisopropyl)-2-oxazolinium tetrafluoroborate and 8 $\mathrm{mol} \% \quad N$-(2-methoxyethyl)methacrylamide. Products were unequivocally identified by spectroscopic comparison to authentic materials prepared by alternate routes.

\section{Reaction of IPO $\cdot \mathrm{H}_{2} \mathrm{SO}_{4}$ with Other Nucleophilic Reagents}

Sodium Bisulfite. To a solution of IPO $\cdot \mathrm{H}_{2} \mathrm{SO}_{4}$ $\left(1.04 \mathrm{~g}, 5 \times 10^{-3} \mathrm{~mol}\right)$ in $2.0 \mathrm{~g}$ of $\mathrm{D}_{2} \mathrm{O}$ was added sodium bisulfite $\left(0.52 \mathrm{~g}, 5 \times 10^{-3} \mathrm{~mol}\right)$. After 5 hours at room temperature, ${ }^{1} \mathrm{H}$ NMR spectroscopy indicated complete conversion to $\mathrm{O}_{3}{ }^{\ominus} \mathrm{S}-\mathrm{CH}_{2}-$ $\mathrm{CD}\left(\mathrm{CH}_{3}\right)-\mathrm{CO}_{2}-\left(\mathrm{CH}_{2}\right)_{2}-\mathrm{NH}_{3}{ }^{\oplus}$. This product was isolated as a white solid from methanol, $\mathrm{mp} 250$ $251{ }^{\circ} \mathrm{C} .{ }^{1} \mathrm{H}$ NMR $\left(\mathrm{D}_{2} \mathrm{O}\right)$ exhibited the following responances: $\delta 4.30\left(\mathrm{t},-\mathrm{CO}_{2}-\mathrm{CH}_{2}-\right), 3.30(\mathrm{t}$, $\left.-\mathrm{CH}_{2}-\mathrm{NH}_{3}{ }^{\oplus}\right), 3.13\left(\mathrm{~d},-\mathrm{CH}_{2}-\mathrm{SO}_{3}{ }^{\ominus}\right)$, and $1.25(\mathrm{~s}$, $\left.-\overline{\mathrm{CD}}\left(\mathrm{CH}_{3}\right)\right)$. When this reaction was run in water the product exhibited an upfield signal as a doublet; $-\mathrm{CH}\left(\mathrm{CH}_{3}\right)$ at $1.28 \mathrm{ppm}$.

Pyridine. Stoichiometric amounts of IPO $\cdot \mathrm{H}_{2} \mathrm{SO}_{4}$ and pyridine in $\mathrm{D}_{2} \mathrm{O}$ gave a white intractable syrup with the following NMR signals: $\delta 7.66-9.09(\mathrm{~m}$, pyridinium moiety), $4.97\left(\mathrm{~d}, \equiv \mathrm{N}^{\oplus}-\mathrm{CH}_{2}\right), 4.46(\mathrm{t}$, $\left.-\mathrm{CO}_{2} \mathrm{CH}_{2}\right), 3.43\left(\mathrm{t}, \mathrm{NH}_{3}^{\oplus}-\mathrm{CH}_{2}^{-}\right)$, and $1.40(\mathrm{~s}$, $-\mathrm{CD}\left(\overline{\mathrm{CH}_{3}}\right)-$.

Hydrogen Chloride. Anhydrous $\mathrm{HCl}(0.1 \mathrm{~g}$, $2.7 \times 10^{-3} \mathrm{~mol}$ ) was absorbed in $0.5 \mathrm{~g}$ of $\mathrm{CD}_{3} \mathrm{CN}$. Adding IPO $\left(0.1 \mathrm{~g}, 9.0 \times 10^{-4} \mathrm{~mol}\right)$ to this solution gave an instantaneous mixture of IPO $\cdot \mathrm{HCl}$ (about $85 \mathrm{~mol} \%$ ) and the Michael adduct of IPO and $\mathrm{HCl}$ $(15 \mathrm{~mol} \%)$ as determined by ${ }^{1} \mathrm{H}$ NMR. IPO $\cdot \mathrm{HCl}$ exhibited the following signals in $\mathrm{CD}_{3} \mathrm{CN}: \delta$ 6.38/5.99 (s, $\mathrm{CH}_{2}=\mathrm{C}-$ ), 4.91 ( $\left.\mathrm{r},-\mathrm{CH}_{2}-\mathrm{O}-\right)$, 4.07 (t, 
$\left.-\mathrm{CH}_{2}-\mathrm{N}^{\oplus} \equiv\right), \quad$ and $\quad 2.05 \quad\left(\mathrm{~s}, \quad \mathrm{C}=\mathrm{C}-\left(-\underline{\mathrm{CH}_{3}}\right)\right)$. Distinguishing signals for the Michaels adduct were observed at: $\delta 2.80\left(\mathrm{q},-\mathrm{CH}\left(\mathrm{CH}_{3}\right)\right)$ and $1.42(\mathrm{~d}$, $-\mathrm{CH}\left(\mathrm{CH}_{3}\right)$ ). Allowing the sample to stand at room temperature for 24 hours caused complete transformation to ring-opened products. The resulting major product, $N$-(2-chloroethyl)methacrylamide, gave the following NMR signals: $\delta 5.60 / 5.30(\mathrm{~s}$, $\left.\mathrm{CH}_{2}=\mathrm{C}-\right), 3.51\left(\mathrm{~m}, \mathrm{NH}-\left(\mathrm{CH}_{2}\right)-\mathrm{Cl}\right)$, and 1.91 (s, $\overline{\mathrm{C}=\mathrm{C}}-\mathrm{CH}_{3}$ ). This product was identical in all respects to authentic material prepared from methacryloyl chloride and aziridine according to the method of Bestian et al. ${ }^{12}$

\section{Type-I. Dimerizations}

Trifluoromethane sulfonic-acid salt of IPO was synthesized and isolated as previously described and used in this procedure. Alternatively this salt was generated in situ and dimerized as follows. Trifluoromethanesulfonic acid $(3.0 \mathrm{~g}, 0.02 \mathrm{~mol})$ was dissolved in acetonitrile $(6 \mathrm{~g})$, cooled in a dry iceacetone mixture and stirred while IPO $(2.22 \mathrm{~g}, 0.02$ mol) was added dropwise over a period of 5 minutes. This sample was allowed to warm up to $15^{\circ} \mathrm{C}$ at which point a second portion of IPO $(2.22 \mathrm{~g}$, $0.02 \mathrm{~mol}$ ) was added dropwise to this stirred solution. An immediate exotherm $\left(15^{\circ} \mathrm{C} \rightarrow 56^{\circ} \mathrm{C}\right)$ was noted accompanied by the formation of a white salt-like product which weighed $1.02 \mathrm{~g}, \mathrm{mp} 216$ $217^{\circ} \mathrm{C}$; yield $18 \%$.

Anal. Calcd. for $\mathrm{C}_{14} \mathrm{H}_{20} \mathrm{~F}_{6} \mathrm{~N}_{2} \mathrm{O}_{8} \mathrm{~S}_{2}: \mathrm{C}, 32.2 \% ; \mathrm{H}$, $3.87 \%$; N, 5.36\%. Found: C, $32.5 \%$; H, $4.00 \%$; N, $5.62 \%$.

The proton spectrum (DMSO- $d_{6}$ ) was assigned as shown in Figure 3 based on integration values and chemical shift comparisons to authentic reference samples. $\mathrm{A}^{13} \mathrm{C}$ spectrum (DMSO) contained several distinguishing features. A signal at $177.1 \mathrm{ppm}$ was assigned to the carbon contained in the fused juncture between the 5- and 8-membered rings. Signals at 72.0 and $60.8 \mathrm{ppm}$ were assigned to $-\mathrm{O}-\mathrm{CH}_{2}-$ and $\equiv \mathrm{N}^{\oplus}-\mathrm{CH}_{2}-$ groups, respectively. Virtually overlapping signals at 15.56 and 15.45 ppm were believed to be due to slight conformational differences in the otherwise identical methyl groups attached to the 8-membered ring in $\left(\mathbf{V}^{\prime}\right)$. Reduction of the filterate from above gave an amorphous, white solid residue. Dissolution in acetonitrile and precipitation with diethyl ether gave a white powdery solid, $\left(\mathrm{mp} 94-98^{\circ} \mathrm{C}\right)$. Attempts to further purify by recrystallization or isolate the dication by further protonation led to intractable syrups. NMR analysis (see Figure 2), protonation experiments and ${ }^{13} \mathrm{C}$ spectroscopy suggest it was a mixture of unprotonated (IV) and monocation (V). The ${ }^{13} \mathrm{C}$ spectrum contained a signal at $176.9 \mathrm{ppm}$ for the carbon at fused juncture in the monocation (V) and signals at $168.6 \mathrm{ppm}$ and $167.8 \mathrm{ppm}$ which were assigned to the unprotonated ketene aminal and pendant oxazoline ring carbons. The methyl region was more complex than for the highermelting dimer with signals at $15.0,14.5$, and 14.2 ppm.

\section{Type-II. Ring-Preserved Oligomerizations}

2-Isopropenyl-2-oxazolinium bisulfate $(10.45 \mathrm{~g}$, $0.05 \mathrm{~mol}$ ) slurried in $35 \mathrm{ml}$ of anhydrous acetonitrile, was stirred as neat IPO $(5.55 \mathrm{~g}, 0.05 \mathrm{~mol})$ was added dropwise over a period of five minutes. After nearly all of the IPO had been added, the reaction mixture became homogeneous and exothermed $\left(25^{\circ} \mathrm{C} \rightarrow 36^{\circ} \mathrm{C}\right)$ as a white, syrupy material fell out of solution. Strirring was continued for 15 minutes, followed by the addition of $20 \mathrm{ml}$ of anhydrous diethyl ether. The syrup was triturated until it had converted into a white, workable solid powder. Filtration gave $12.54 \mathrm{~g}(78 \%)$ of a white, hygroscopic solid which after trituration with two more $15 \mathrm{ml}$ portions of ether melted at $80-84^{\circ} \mathrm{C}$ (evolution of gas). The proton spectrum (DMSO- $d_{6}$ ) was assigned as shown in Figure 4(A) based on chemical-shift comparison with authentic model compounds. Adding $\mathrm{D}_{2} \mathrm{O}$ to this oligomer gave a much more simplified spectrum as shown in Figure 4(B). The spectrum of this hydrolysis product was essentially identical to that (Figure 5) obtained for the Type-III ring-opened oligomers.

\section{Type-III. Linear 2-Position Ring-Opened Oligomers}

Ring-Opened Dimers and Low-Molecular-Weight Oligomers. An aqueous solution of concd $(11.6 \mathrm{M})$ $\mathrm{HCl}(21.9 \mathrm{~g})$, water $(27.0 \mathrm{~g})$, and $\mathrm{CuCl}_{2} \cdot 2 \mathrm{H}_{2} \mathrm{O}$ $(20 \mathrm{mg})$ was cooled to $<5^{\circ} \mathrm{C}$. Aqueous IPO $(56 \mathrm{~g}$, $0.19 \mathrm{~mol}$ ) was then added until $\mathrm{pH}=1$. A sample was taken $(10 \mathrm{ml})$ and IPO addition was continued with samples being withdrawn at $\mathrm{pH}=1.5,2.0$, and 3.0. The samples were maintained at $30^{\circ} \mathrm{C}$ and the reaction was monitored by HPLC. The major product was 2-aminoethyl methacrylate which exhibited the following spectral data: ${ }^{1} \mathrm{H}$ NMR $\delta 1.92$ 
(s, 3H), $\left.\mathrm{CH}_{3}-\mathrm{C}=\mathrm{O}\right), 3.37$ (t, $\left.(2 \mathrm{H}),-\mathrm{CH}_{2}-\mathrm{NH}_{3}{ }^{\oplus}\right)$, $4.38\left(\mathrm{t},(2 \mathrm{H}),-\mathrm{CO}_{2}-\mathrm{CH}_{2}-\right), 5.70$ and $6.10 \mathrm{ppm}(\mathrm{s},(\mathrm{H})$,

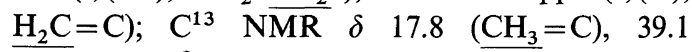
$\left(-\mathrm{CH}_{2}-\mathrm{NH}_{3}{ }^{\oplus}\right), 61.6\left(-\mathrm{CO}_{2}-\mathrm{CH}_{2}-\right), 128.0\left(\underline{\mathrm{H}_{2} \mathrm{C}}=\right.$ C), $135.3\left(\mathrm{CH}_{2}=\mathrm{C}=\right)$, and $168.8\left(-\mathrm{C}^{-} \mathrm{O}\right)$. The other product observed by HPLC was the dimer: ${ }^{1} \mathrm{H}$ NMR $\delta 1.31\left(\mathrm{~d},(3 \mathrm{H}), \mathrm{CH}_{3}-\mathrm{CH}\right), 1.92(\mathrm{~s},(3 \mathrm{H})$, $\left.\mathrm{CH}_{3}-\mathrm{CH}=\mathrm{C}\right), 3.47\left(\mathrm{~m},(\overline{7 \mathrm{H}}),-\mathrm{CHNH}_{2}{ }^{\oplus}-\mathrm{R}\right.$ and $\left(\mathrm{H}_{3}-\mathrm{CH}\right), 4.38\left(\mathrm{t},(4 \mathrm{H}),-\mathrm{CO}_{2} \mathrm{CH}_{2}\right), 5.70 / 6.10(\mathrm{~s},(1 \mathrm{H})$, $\left.\mathrm{CH}_{2}=\mathrm{C}\right) ; \mathrm{C}^{13} \mathrm{NMR} \delta 14.7\left(\mathrm{CH}_{3}-\mathrm{CH}\right), 17.9$ $\left(\mathrm{CH}_{3} \mathrm{C}=\right), 36.6 \quad\left(\mathrm{CH}_{2}-\mathrm{CH}-\mathrm{CH}_{3}\right), 38.3 \quad\left(\mathrm{CH}_{2}-\right.$ $\left.\overline{\mathrm{NH}_{3}}{ }^{\oplus}\right), 47.3$ and $\left.49.6 \overline{\left(\mathrm{CH}_{2}\right.}{ }^{\oplus}-\mathrm{NH}_{2}-\mathrm{CH}_{2}\right), \overline{60.3}$ and $62.1\left(\mathrm{CO}_{2} \mathrm{CH}_{2}\right), 128.0\left(\mathrm{CH}_{3}-\mathrm{C}=\mathrm{O}\right), 135.2$ $\left(\mathrm{CH}_{2}-\mathrm{CCH}_{3}\right), \quad \overline{168.6}\left(\mathrm{CH}_{2}=\overline{\left.\mathrm{C}\left(\mathrm{CH}_{3}\right) \mathrm{CO}_{2}\right)}\right.$, and 194.6 ppm ( $\left.-\mathrm{CH}-\mathrm{CO}_{2}-\right)$. After 20 hours IPO was completely consumed and final analysis of products at various pH's is as shown below.

\begin{tabular}{ccc}
\hline $\mathrm{pH}$ & $\mathrm{mol} \%$ of AEM & mol $\%$ of dimer \\
\hline 1.0 & $98 \%$ & $1.2 \%$ \\
1.5 & $97 \%$ & $2.0 \%$ \\
2.0 & $89 \%$ & $9.6 \%$ \\
3.0 & $51 \%$ & $20.7 \%$ \\
\hline
\end{tabular}

The $\mathrm{mol} \%$ of dimer was also determined by ${ }^{1} \mathrm{H}$ NMR based on the areas of the methyl protons at $\delta=1.93$ and 1.33. At pH 1.0, 1.5, 2.0, and 3.0, the $\mathrm{mol} \%$ of dimer was estimated to be $1.2,3.2,7.6$, and $31.7 \%$.

\section{Higher-Molecular-Weight Ring-Opened Oligomers}

Procedure A. Aqeuous IPO $(80 \mathrm{wt} \%)$ was added slowly to a solution of concd $\mathrm{HCl}(15.8 \mathrm{~g}$, $0.156 \mathrm{~mol})$ and $12 \mathrm{mg} \mathrm{CuCl} \mathrm{Cu}_{2} \cdot 2 \mathrm{H}_{2} \mathrm{O}$ over a period of $90 \mathrm{~min}$, while cooling $\left(<5^{\circ} \mathrm{C}\right)$ until the $\mathrm{pH}$ reached 3.4. A total of $23.9 \mathrm{~g}(0.17 \mathrm{~mol})$ of IPO were required. The reaction mixture was allowed to warm up to room temperature which after $30 \mathrm{~min}$ gave a $\mathrm{pH}=4.8$ and a small amount of white solid precipitate. The $\mathrm{pH}$ was adjusted to 2.2 with concd $\mathrm{HCl}$ and allowed to stir for 24 hours. The white gummy solid was filtered, slurried in $\mathrm{CH}_{3} \mathrm{CN}$ and filtered (3X) to give $270 \mathrm{mg}$ (yield. $1 \%$ ) of a fine white powder. This solid was nearly insol in $\mathrm{H}_{2} \mathrm{O}$, but quite soluble in a mixture of $\mathrm{H}_{2} \mathrm{O}-\mathrm{CF}_{3} \mathrm{CO}_{2} \mathrm{H}$. The ratio of methyl groups ( $\delta=1.31 / 1.93 \mathrm{ppm})$ was $\cong 15$ and the remainder of the spectrum was consistent with the proposed structure (degree of oligomerization $\cong 15): \quad \delta 1.31 \quad\left(\underline{\mathrm{CH}_{3}} \mathrm{CH}\right), \quad \delta 1.93$ $\left(\mathrm{CH}_{3}-\mathrm{C}=\mathrm{C}\right), \quad \delta 5.47 \quad\left(\mathrm{CH}_{2}-\mathrm{N}\right.$ and $\left.-\mathrm{CH}-\mathrm{CH}_{2}-\right)$, and $\delta 4.39 \mathrm{ppm}\left(-\mathrm{CO}_{2}-\overline{\mathrm{CH}_{2}}\right)$.

Procedure B. A stoichiometric amount of IPO $(1.11 \mathrm{~g}, 0.01 \mathrm{~mol})$ was added dropwise to a stirred solution of $\mathrm{CD}_{3} \mathrm{CO}_{2} \mathrm{D}(0.6 \mathrm{~g}, 0.01 \mathrm{~mol})$ in $1.5 \mathrm{~g}$ of $\mathrm{D}_{2} \mathrm{O}$. The oligomerization was monitored by ${ }^{1} \mathrm{H}$ NMR, with complete conversion being noted in 23 hours at room temperature. Figure 5 is a spectrum of this oligomeric product and was essentially identical to oligomer resonances described above. Integration of methyl resonances at 1.90 and 1.23 showed their presence in a ratio of $1: 4.75$, thus indicating $n \cong 4.75$.

Anionic Polymerization of IPO. Using flame-dried equipment, a nitrogen blanket and brine-ice cooling, butyllithium $(4.45 \mathrm{ml}, 2.25 \mathrm{~mol})$ was added dropwise to a stirred solution of IPO $(9.90 \mathrm{~g})$ in $25 \mathrm{ml}$ of tetrahydrofuran using precautions and techniques described by Miller. ${ }^{13}$ Addition was made at such a rate as to maintain temperature under $5^{\circ} \mathrm{C}$. After $3.34 \mathrm{ml}$ of lithium reagent had been added, the reaction mixture exothermed to $30^{\circ} \mathrm{C}$. Addition was completed without further exotherm, followed by addition of $10 \mathrm{ml}$ of water. A white precipitate fell out which was filtered and crystallized out of methanol. The product weighed $9.33 \mathrm{~g}(94 \%)$. It was soluble in benzene, methanol, tetrahydrofuran, or water, however, it was not soluble in mixtures of the later two solvents. Characteristic infrared absorption bands for the oxazoline ring $\left(\sim 950 \mathrm{~cm}^{-1}\right)$ and $\mathrm{C}=\mathrm{N}$ at $1650-1660 \mathrm{~cm}^{-1}$ were noted. ${ }^{1} M_{w}=2249$, $M_{n}=1447, M_{w} / M_{n}=1.55$ as determined by gelpermeation chromatography.

Anal. Calcd for $\left(\mathrm{C}_{6} \mathrm{H}_{9} \mathrm{NO}\right)_{n}: \mathrm{C}, 64.8 \% ; \mathrm{H}, 8.16 \%$; $\mathrm{N}, 12.60 \%$. Found: C, $64.5 \%$; H, $8.12 \%$; N, $12.42 \%$.

${ }^{13} \mathrm{C}$ NMR of the anionically polymerized IPO was virtually identical to that polymerized with azo catalysts. ${ }^{1}$ Most notable was a signal at 172.64 ppm in each case assigned to the 2-position carbon in the oxazoline ring.

Acknowledgments. The authors wish to express their gratitude to Dr. T. A. Chamberlin for helpful discussions and to Dr. P. Smith for portions of the ${ }^{13} \mathrm{C}$ spectroscopic analysis.

\section{REFERENCES}

1. D. A. Tomalia, "Functional Monomers," R. H. 
Yocum and E. B. Nyquist, Ed., Vol. 2, Marcel Dekker, Inc., New York, N.Y., 1974, pp 71-91.

2. T. Kagiya, T. Matsuda, and K. Zushi, J. Macromol. Sci, Chem., A6, 1349 (1972).

3. T. Kagiya and T. Matsuda, Polym. J., 3, 307 (1972).

4. D. A. Tomalia and D. P. Sheetz, J. Polym. Sci., A-1, 4, 2253 (1966).

5. T. Kagiya, T. Matsuda, and R. Hirata, J. Macromol. Sci., Chem., A6, 451 (1972).

6. T. Saegusa, H. Ikeda, and H. Fujii, Macromolecules, 5, 359 (1972).

7. P. Allen, Jr. and J. Ginos, J. Org. Chem., 28, 2759 (1963).

8. W. Seeliger, E. Aufderhaar, W. Diepers, R. Feinauer, R. Nehring, W. Thier, and H. Hellmann, Angew.
Chem. Int. Ed., 5, 885 (1966).

9. A. I. Meyers and A. C. Kovelesky, Tetrahedron Lett., 22, 1783 (1969).

10. S. Fujioka, T. Ichimura, and Y. Shinohara, Kogyo Kagaku Zasshi, 69, 732 (1966).

11. P. Bieber, Ann. Chem. (Paris), Ser. 12, 9, 674 (1954).

12. H. Bestian, Justus Liebigs Ann. Chem., 566, 210 (1950).

13. D. B. Miller, "Preparative Methods of Polymer Chemistry," W. R. Sorenson, and T. W. Campbell, Ed., 2nd ed, Interscience Publishers, New York, N.Y., 1968, p 279.

14. D. A. Tomalia and J. N. Paige, J. Org. Chem., 38, 422 (1973). 